\title{
INFLUXOS DA TRANSFORMAÇÃO DO «STATUS» E DO PAPEL DA MULHER SOBRE A NATALIDADE*
}

\author{
Maria Olivia Dias
}

\section{INTRODUÇÃO}

\subsection{O Tema}

Não existe conduta sem motivação, mas para que haja motivação é necessário que o estímulo externo solicite o espírito para que este se possa pôr em acção.

Isto sucede também em relação ao tema do nosso trabalho: OS INFLUXOS DA TRANSFORMAÇÃO DO «STATUS»E DO PAPEL DA MULHER SOBRE A NATALIDADE. Portanto, dentro dos nossos limites, a finalidade do nosso trabalho é ver se e como a nova condição da mulher incide sobre um dos principais aspectos da dinâmica demográfica: a natalidade.

Além disso procuramos descobrir quais são os principais factores que provocam tal mudança. Tudo isto tendo em atenção a diversidade de população, que certamente se reflecte numa diferença dos comportamentos demográficos em geral, e nos comportamentos procriativos em particular.

\subsection{Actualidade do nosso argumento}

No decurso do nosso século pela primeira vez a mulher tomou posse da palavra e da escrita, que podemos dizer que, no espaço de trinta anos, se publicaram mais livros que em trinta séculos; isto faz-nos subentender o interesse e a importância pela temática da mulher nas suas componentes físicas, psíquicas e religiosas.

Assim, o nosso tema é uma pequena parcela da questão da mulher que, nos nossos dias, assume um grande significado. São diversos os cientistas que estudam e se dedicam aos problemas demográficos, entre os quais se encontram economistas, especialistas da família, sociólogos e psicólogos. Não só com análises quantitativas mas sobretudo qualitativas, procuram dar uma explicação do facto tal como ele se apresenta na realidade. Mas sabemos quão pobres são os 
dados de uma e outra natureza, que da nossa parte não é possível fazer, por agora, um trabalho exaustivo do problema. Mas não queremos com isto dizer que a ausência de dados signifique ausência de actualidade ou de falta de interesse. Pelo contário, a actualidade do tema consiste no próprio empenho verificado em se adquirirem elementos que, com maior probabilidade, dêem resposta às questões actuais. É próprio desta procura incessante que lhe dá toda a originalidade e o torna de peculiar actualidade ${ }^{1}$.

\subsection{Significado da transformação do «status» e do papel da mulher}

Sem entrarmos em detalhes inúteis, parece-nos que vale a pena esclarecer brevemente em sentido estrito o significado dos termos «status» e papel, no contexto social. Os dois termos cobrem factos sociais que são conceptualmente difíceis de distinguir. Estes definem-se e, sobretudo, os respectivos significados correlacionam-se, daí que por vezes se diga que o «status» é o que se pensa que alguém é, e que o papel é o que se pensa que alguém faz. A avaliação, a estima e o juízo dos outros intervêm nos conceitos, tanto do papel como do «status» da pessoa. Assim, por definição, o «status» indica a posição de uma pessoa na sociedade. $O$ papel, por sua vez, refere-se à função que o indivíduo desempenha ${ }^{2}$.

$\mathrm{O}$ «status» tem uma conotação mais estática e por isso passiva em relação ao papel, que é dinâmico e activo. Deste modo, quando se faz uma distinção clara, os dois conceitos, na situação social concreta, são considerados comuns, mas com conotações diferentes.

A evolução e a mudança que caracterizaram, de modo significativo, o mundo de hoje não exclui a mulher. Sobretudo nas sociedades industrializadas, uma modificação profunda interveio no «status» e no papel da mulher. As transformações tecnológicas, económicas e sociais emergem de modo particular na mudança do «status» e papel da mulher ${ }^{3}$.

Não obstante todos os esclarecimentos, o conceito de «status» e papel da mulher não tem sido muito claro, a ponto de se the atribuir termos tais como: autonomia feminina, desigualdade com base no sexo, etc. Os novos estudos tendem a aproximar-se mais da realidade, insistindo frequentemente sobre os seguintes factores: "prestígio da mulher», "poder da mulher», «controlo exercido pela mulher», etc. Tais conceitos, de per si, não definem o «status» da mulher, mas são a base da sua construção. Não queremos com isto dizer que a mulher anteriormente não tivesse um «status», uma posição, um papel, mas o facto está em serem considerados numa situação muito especial. A diferença que nos parece mais fundamental em relação à anterior é que a elevação do «status» da mulher tem consistido em querer ser ela própria a procurá-lo, depois de reconhecido, aceite ou não, segundo os tipos de sociedade. Não podemos deixar de dizer que as culturas, tradições, costumes e valores são factores que contribuem, pelo 
menos, para a elevação do «status» e do papel da mulher, quer na família, quer na sociedade.

Estas circunstâncias servem-nos como indicadores da falta de um «status» bem definido e universalmente aceite ${ }^{4}$. Há diferenças de umas regiões para outras, bem como entre as diversas classes, porém a ambiguidade existe também na mente das mulheres. São elas muitas vezes as próprias a não definirem bem a sua posição.

Em todo o caso, as revistas, a televisão, a rádio, os livros, as conferências, etc., mostram bem como a sua posição se tem modificado, pois os direitos teóricos e abstractos têm-se traduzido, em muitos casos, em termos concretos.

$\mathrm{O}$ «status» da mulher e o próprio conceito de papel assumem, assim, um reconhecimento valorativo, os quais, em certa medida, vinham sendo penalizados pela história, atribuindo-lhes a função para a qual a sociedade considerava que ela tinha nascido: a mulher ao serviço da maternidade. Hoje uma nova concepção faz com que se invertam os termos: a maternidade ao serviço da mulher.

Debate-se, no reconhecimento que a maternidade assume, considerando-se o sentimento humano daquela, o modo e as condições do seu desenvolvimento, as motivações interiores, as quais variam com as alterações de diversas coordenadas: demográficas, sociais, económicas, etc., sentindo-se portanto a influência e mudanças culturais até que se tornem costumes.

Assim, «status» e papel da mulher são interligados entre si e vistos pela complexidade das suas interacções, e os factores culturais e biológicos a eles ligados exercitam uma influência determinante na sua evolução, bem como nos seus comportamentos procriativos 5 .

Parece poder afirmar-se que a mudança do «status» e papel da mulher conseguiram modificar, ao mesmo tempo, a composição da família ${ }^{6}$ e, por isso, alterar a sua tradicional redução à procriação.

\subsection{Dimensão e Delimitação}

A problemática não pode ser vista numa linha micro- sociológica, pois esta apresenta-se na realidade numa perspectiva macro-sociológica. A vastidão de causas ou, por outro lado, os factores que a determinam são muitos e complexos. Querer focar o tema globalmente, num trabalho como este, pode correr-se o risco de generalizar de tal modo o assunto que se optou por fazer estudo científico mas, como dissemos, limitado somente ao influxo das transformações do «status» e do papel da mulher sobre a variável demográfica: a natalidade.

Tal trabalho, embora muito limitado, não significa que se monosprezem outras variáveis que, de certo modo, também recebem modificações derivadas do «status» e do papel da mulher, assim como outros factores incidentes, de um modo ou outro, na realidade. Tratamos simplesmente do «status» e do papel da mulher, por nos parecer terem sido estes alguns dos mais vinculados à nova condição da mulher, os influenciadores na diminuição da natalidade. Podemos, deste 
modo, dizer que existe uma correlação acentuada entre diminuição da natalidade e mudança da condição da mulher ou, mais precisamente, do seu «status» e papel.

Não esqueçamos que os factores da diminuição da fecundidade, vistos nos seus aspectos principais - económicos, culturais, religiosos, psicológicos, fisiológicos - , sugerem uma necessidade de estudos, feitos segundo as diversas culturas, para assim podermos fazer um confronto com a realidade mundial, no âmbito da problemática da condição da mulher, bem como no âmbito da problemática político-demográfica-ambiental. Como é sabido, prevalecem interpretações e compreensões com dinâmicas diferentes, segundo a evolução das sociedades com suas características próprias ${ }^{7}$, que não é possível darmos uma visão global da situação. Acentuaremos uma ou outra que nos pareça mais importante, sem termos a pretensão de quantificar ou qualificar todas as possíveis circunstâncias e actualidades da realidade que se vive por toda a parte, embora com critérios diversificados.

Como o grau de controlo da fecundidade é resultado de uma complexa escolha, que coenvolve a personalidade da mulher, estamos longe de explicar aquele complexo comportamento individual que se diferencia segundo os tempos e os lugares onde se desenvolve.

Com base nestas considerações, queremos sublinhar que os factores que influenciam a fecundidade humana são muitos e complexos, nas suas interrelações, difíceis de analisar. Por isso, é compreensível que, na nossa escolha, quiséssemos concentrar a atenção sobre aqueles que parecem ter sido os que, cronologicamente ${ }^{8}$, mais influenciam, nas suas manifestações sobre a natalidade, as quais são: o trabalho extradoméstico, a instrução e o controlo da mulher sobre os contraceptivos. Estes não influenciam isoladamente, mas são interdependentes uns dos outros. Por isso, estão tomados em consideração somente os principais, isto é, os que se relacionam com a nova condição do «status» e papel da mulher.

\section{INFLUXOS DERIVADOS DO TRABALHO EXTRADOMÉSTICO}

Segundo a teoria «new home economics», é atribuído ao trabalho extradoméstico ${ }^{9}$ da mulher as modificações das escolhas em termos de procriação ${ }^{10}$.

O declínio da natalidade que se pode observar em todos os países industrializados é, em parte, explicado por demógrafos, economistas, historiadores e sociólogos, considerando sempre o trabalho extradoméstico da mulher como um dos factores que determina a emancipação da mulher, mas que também condiciona $o$ fenómeno da natalidade, em termos de redução do número de filhos ${ }^{11}$.

$\mathrm{O}$ trabalho extradoméstico, embora não sendo considerado, explicita e directamente, como factor que influencia sobre a natalidade, mas é óbvio que assim suceda, já que as variáveis explicativas que se consideram são aquelas que se poderiam qualificar como finais, enquanto já são resultantes da influência de 
outras variáveis como: mudança da estrutura social, tipo de cultura, etc. (cfr. Trab..$^{\circ} 1 \mathrm{e} 2$, em apêndice).

$\mathrm{O}$ trabalho extradoméstico interpretado, neste sentido, é um dos fortes indicadores que intervem como elemento primário nas condições familiares e, por isso, na condição da mulher, nas opções em determinar, em termos de custos-benefícios, a oportunidade do nascimento de um primeiro filho ou de um segundo. Evidentemente, o papel fundamental do «status», derivado da nova condição da mulher, inserida no trabalho, modifica o estilo de vida, muda as relações e o poder no interior da família, muda as suas aspirações e perspectivas. Em termos de prol, esta resulta condicionada também pelo trabalho extradoméstico da mulher.

\subsection{A mulher é menos disponível para a família}

\subsubsection{Materialmente}

Hoje a mulher afasta-se da casa para desempenhar um trabalho extradoméstico, não sendo este, na maioria dos casos, um trabalho alternativo ao trabalho doméstico, mas um que se vem acrescentar a este. Naturalmente a mulher fica com menos tempo para dedicar à família e, por isso, menos disponível para os filhos.

Das investigações que se têm feito sobre a relação entre o trabalho da mulher e natalidade, é decisivamente notável como a fecundidade é mais baixa entre as mulheres com actividade extradoméstica. Por isso, o trabalho extradoméstico da mulher é tido como variável explicativa nas diferenças da fecundidade ${ }^{12}$. Portanto, a taxa das mulheres ocupadas no trabalho extradoméstico decresce quando cresce o número de filhos. Ao invés, aumenta quando diminui o número de filhos ${ }^{13}$.

Tal descrição vale para a Europa e Ásia, segundo a interpretação de KAREN, mas é falsa para a África ${ }^{14}$. A autora apresenta três razões para isso: a) primeiro, porque em África os filhos são considerados mão-de-obra e, por isso, contribuem para a economia da família; b) segundo, não existindo uma eficiente assistência nas doenças, nascem muitos mas também morrem muitos, pelo que a mulher pensa num maior número para recompensar; c) terceiro, a mulher pode ir trabalhar fora, porque os filhos, já com 6-7 anos de idade, são responsáveis pelos mais pequenos, bem como pelas pessoas de mais idade ou incapacitadas de trabalhar. Daí que, nos países desenvolvidos, um filho é peso para a mãe, geralmente até terminar um curso (25-27 anos), pois é a mãe que deve estar disponível para os seus cuidados. Inversamente, nos países subdesenvolvidos, com aquela idade já dedicaram quase uns vinte anos ao serviço da família.

Nestas condições, é de termos em conta, como dissemos na introdução, que a cultura e o desenvolvimento de cada país são importantes para interpretarmos materialmente a disponibilidade da mulher para a família. Entra todo um com- 
plexo de factores que não serão considerados neste nosso contexto, embora merecessem ser tratados. Por mais diferentes que sejam as culturas, o fenómeno verifica-se geralmente.

\subsubsection{Psicologicamente}

A relação trabalho extradoméstico da mulher e natalidade, do ponto de vista psicológico, não tem sido, geralmente, analisada, tanto na sua complexidade como na sua profundidade. Não obstante existir, entre psicólogos e sociólogos, uma certa convicção que o trabalho extradoméstico leva a mulher a inserir-se numa actividade produtiva e que esta a liberta da subordinação nos confrontos com o homem, uma verdadeira análise, sob uma perspectiva psicológica, ainda não deu respostas concretas a tal problema.

No entanto, das descrições feitas subjectivamente, aqui e além, podemos formular a hipótese de que, psicologicamente, o trabalho extradoméstico tem um significado central na vida da mulher, quanto à procriação. Embora ele lhe cause uma maior fadiga mas, ao mesmo tempo, traz-lhe novas experiências que estão em sintonia com o seu modo de ser e viver.

As circunstâncias em que a mulher, com o trabalho extradoméstico, se confronta psicologicamente, levam-na a ter menos vontade de ter filhos, encontrando nestes, de certo modo, um obstáculo à sua liberdade e daí menor exigência em relação à procriação.

A mulher muitas vezes renuncia à casa e à família, para não suportar a fadiga do duplo papel, querendo, como qualquer pessoa, desenvolver a sua personalidade, colocando os seus interesses individuais e as suas aspirações em primeiro $\operatorname{lugar}^{15}$. Por isso, para a maioria de algumas categorias de mulheres, tornou-se um estímulo descobrir o trabalho extradoméstico, podendo optar por uma realização mais digna.

Ao discutir tal problema é preciso especificar que falamos de mulheres nas sociedades industrializadas, pois sabemos bem que não existe um «problema da mulher», referente a todas. São diferentes as dificuldades e necessidades psicológicas com que a mulher se debate.

Sabemos que a mulher é actualmente mais madura e tem necessidade de realizar a sua formação, como princípio de referência das opções, pensamentos, comportamentos, como única condição de autonomia psicológica, efectivamente válida, para poder optar por escolhas existenciais. Manifesta, assim, uma capacidade de autogestão psicológica, que é condição primária para a liberdade na escolha daquilo que lhe dá valor como pessoa e como pessoa «concreta». 


\subsection{A mulher tem mais conhecimentos do modo como evitar os filhos}

\subsubsection{Através de uma maior solidariedade entre colegas de trabalho}

O ambiente fechado, a que a mulher era submetida, não lhe permitia grande liberdade de diálogo com as pessoas extra- familiares, por vezes só possível com qualquer vizinha, mas o trabalho extradoméstico abriu-lhe outras perspectivas. As comunicações e os contactos, no grupo de trabalho, deram-lhe possibilidade de maior abertura. Através do trabalho extradoméstico, a mulher adquire conhecimentos sobre si própria, sobre os outros, bem como as suas verdadeiras circunstâncias e possibilidades de dar vida nova à Vida. $\mathrm{O}$ sentido da solidariedade é mais forte, por vezes no grupo de trabalho que no grupo-família. No grupo de trabalho fala-se de todos e de tudo, o que não acontece no ambiente familiar.

Com colegas de trabalho a mulher diz coisas e expõe os seus problemas num diálogo muito mais aberto e franco que na própria família, salvo raras excepções. O medo de a contradizerem, os conceitos de uma educação, por vezes falhada, uma série de outros factores, contribuem para que a mulher se feche em sim mesma, reprimindo a sua maneira de ser, sabendo já, de ante mão, que é melhor não dizer nada. Isto sucede em muitas famílias, o que, em certos casos, se modifica com colegas de trabalho, em diálogo e abertura, sem preconceitos que, erroneamente, existiam.

Assim, em grupo de trabalho procuram dialogar e dar explicações a alguns dos seus próprios problemas, em relação à vida pessoal, relações com família, esclarecimentos de dúvidas em confronto com o homem, etc.

Estes conhecimentos que, para além de as esclarecerem, ajudam-nas a serem mais decisivas, mais destemidas, mais corajosas e a levarem assim uma vida mais activa mas também mais realista. Portanto, com o trabalho extradoméstico, as mulheres descobrem que o seu mundo era mais importante que aquele que lhes propunham e conseguiram uma posição mais humana e mais digna.

Agora, diferentemente do que sucedia noutros tempos, a mulher orienta-se realisticamente, na decisão de ter ou não filhos, descobrindo até modos de os evitar. Daí que o trabalho extradoméstico tenha modificado a posição da mulher. Aquele trouxe-lhe, sem dúvida, perspectivas mais dignas, facto este que não podemos contestar. $\mathrm{O}$ trabalho extradoméstico melhorou a posição e o papel da mulher na família e na sociedade.

\subsubsection{Procurando os meios anticonceptivos e outros}

$\mathrm{Na}$ mesma linha de descrição feita anteriormente, o trabalho extradoméstico não só deu possibilidade de aquisição de conhecimentos à mulher, mas estes são 
agora mais concretamente definidos. É a mulher que, agora, os adquire pessoalmente, sem precisar da intervenção de outras pessoas.

Ouve-se ainda dizer, sobretudo em meios mais desfavorecidos - a uma mulher que praticamente faz só vida de casa - , quando, por exemplo, se fala da pílula, «não conheço tal coisa, nem a quero conhecer». Isto não quer dizer que não utilize qualquer outro meio para limitar o número de filhos, simplesmente $o$ ambiente que a envolve não a desperta para tomar conhecimento dos meios, nem tem facilidade em os adquirir, como tem uma que trabalha fora de casa. Aquela que trabalha fora do ramo familiar não manifesta ignorância, mesmo que não os utilize, ao menos sabe que eles existem e que os pode utilizar quando quiser. Mas esta é a altura, inclusive, de receber informações de colegas sobre os meios anticonceptivos, sem ter que, na maioria dos casos, de recorrer ao médico. Além disso, o trabalho extradoméstico permite-lhe aumentar o seu poder de compra, pois o serviço remunerado tem também essa vantagem.

O problema dos anticonceptivos virá analisado à frente, aqui somente quisemos apontá-lo, devido às repercursões que o trabalho extradoméstico exerceu em conceder à mulher o seu conhecimento, bem como a possibilidade em poder, independentemente, utilizá- los.

\subsubsection{Maior autonomia da mulher}

A mudança mais notória que operou o trabalho extradoméstico na mulher reside no «status» económico. É que, quem manejava o financiamento era o homem e deste dependia aquela quase totalmente. A mulher mostra bem como a sua autonomia financeira é factor essencial na sua realização pessoal ${ }^{16}$.

Com o trabalho extradoméstico, a mulher encontrou caminhos que the dão a possibilidade de poder satisfazer novas aspirações ${ }^{17}$ e de ser ela própria a ter oportunidade de escolher o seu destino.

Portanto, a autonomia da mulher não deve ser interpretada somente com base no aspecto económico. Ela está também ligada às transformações favorecidas por outros factores evolutivos de carácter sócio-cultural. Antes de tudo, o afirmar-se de uma liberdade maior nas decisões, relativas à sua própria vontade em relação às escolhas da procriação.

Os impulsos decisivos da mulher para com uma actividade extradoméstica é uma das características mais objectivas e que mais influência exerce na opção de ter ou não determinado número de filhos. Excepcionalmente existe um certo número de mulheres que, exercendo um trabalho extradoméstico, têm ainda um número de filhos relativamente elevado. São, todavia, casos muito raros.

Deste modo, o processo de transformação do «status» e do papel da mulher, devido ao trabalho extradoméstico, é concomitantemente consequência e causa de uma evolução social complexa, onde naturalmente podemos considerar a natalidade como uma variável dependente destes factores que, em parte, é explicada devido a esta autonomia económico-social da mulher. Hoje, com a sua auto- 
-suficiência, a mulher tem menos medo de uma possível ruptura das relações com o homem, pois é agora mais encorajada e dispõe de capacidade de se governar, sem esperar que o marido a sustente e decida por ela. É tutora da sua pessoa, das suas decisões, das suas escolhas e motivações, pois pode viver autonomamente, sem a intervenção de outrém.

Se o trabalho extradoméstico leva ao aumento do rendimento familiar, por outro lado também satisfaz aquela aspiração de autonomia e de realização da própria personalidade, cada vez mais sentida pela mulher.

A autonomia é também, segundo esta visão, um efeito à rejeição da fecundidade e, por isso, leva à diminuição da natalidade. Deste modo, podemos afirmar com FEDERICI que a mulher, com trabalho extradoméstico, goza de maior autonomia. A autonomia económica constitui um factor de particular importância para a colocação paritária na família e, sobretudo, para a participação nas escolhas da procriaçãa ${ }^{18}$.

\section{INFLUXOS DERIVADOS DA INSTRUÇÃO}

A instrução é cronologicamente o segundo factor estrutural que produziu mudanças no «status» e no papel da mulher na sociedade e na família ${ }^{19}$. Podemos dizer que é actualmente mais importante que o trabalho extradoméstico, pela força que tem em modificar a condição da mulher. A mulher destaca-se com facilidade dos modelos tradicionais para adquirir novos modelos.

Em relação ao nosso tema, as pesquisas feitas sobre a fecundidade demonstram como a instrução é um dos grandes factores que influencia a natalidade. É de notar que aquelas que possuem um diploma de habilitações têm uma maior inclinação para reduzir o número de filhos. E é precisamente nos meios menos desenvolvidos, menos urbanizados e industrializados que se concentra uma maior taxa de natalidade, pelo facto de a procriação ser ainda o papel mais importante desempenhado pela mulher, não se verificando sinais muito evidentes da rejeição do papel relevante da maternidade pela parte da mulher ${ }^{20}$.

\subsection{A mulher mais consciente de si, das suas potencialidades cognoscitivas e operativas}

Não é de admirar que, à mulher, faltasse confiança em si mesma e, por isso, segurança necessária para certas responsabilidades. $O$ efeito da deficiente educação da personalidade que lhe foi conferida, durante muito tempo, é um dos factores que a impediram de assumir-se como uma pessoa capaz de conhecer-se a si propria e de poder obter a sua auto-realização.

O clima sócio-cultural, a educação familiar, com os seus preconceitos, não desenvolviam na mulher aquelas qualidades necessárias a tomar consciência de 
si mesma, favorecendo-lhe, em vez disso, um ideal em completa contradição com a sua personalidade.

Até agora, a mulher viu-se com os olhos e a mentalidade do homem, em função do homem, sem ter responsabilidade de perceber e exprimir as suas próprias potencialidades. Como nota criticamente quem escreve, tratando de análises deformadas e limitadas, bem como de hipóteses estereotipadas ${ }^{21}$, Betty FRIEDAN, no seu livro «La seconda fase», propõe uma reflexão sobre os erros cometidos em relação à mulher, pois são eles uma lesão para todos e um dos pontos mais altos dos quais a mulher tomou consciência ${ }^{22}$.

As obrigações atribuídas à mulher têm sido consideradas deveres naturais e instintivos, definidas a partir da sua estrutura fisiológica, mais que da razão e da liberdade. Sem dúvida que a mulher mais instruída é levada a reivindicar os seus direitos e a efectuá-los com mais consciência. Objectivamente as motivações da mulher são, neste caso, mais de tipo ideal.

A mulher com a instrução conquista uma maior consciência, que raramente encontrava antes, bem como uma nova mentalidade, expulsando o complexo de inferioridade. A sua capacidade intelectual é afirmada pela não aceitação à sujeição dos outros, em nome da deficiência e da própria ignorância ${ }^{23}$.

Podemos certamente afirmar que a frequência escolar é um factor significativo na emancipação da mulher. Os conhecimentos adquiridos parecem entrar, em grande medida, nas suas motivações pessoais. É certo que se pode ser atraído por algo somente quando se conhece.

Maior consciência, maior autonomia, maior possibilidade em evitar o controlo social ligado ao ambiente fechado e restrito da tradição. Em relação à cultura tradicional, a instrução levou a mulher a superá-la, em relação ao marido, a uma maior igualdade em geral e, em particular, na decisão e escolha, quando e quantos os filhos a ter. Foi de certo modo o nível de estudo conseguido pela mulher um dos factores mais importantes que colocou em crise noções e valores tradicionais, no que se refere à fecundidade.

\subsection{Menor constrição da cultura ambiental acerca da função da mulher quanto à procriação}

A consciência geral dos valores democráticos e igualitários da sociedade influenciou notavelmente a mudança do «status» da mulher e este, por sua vez, repercutiu-se na função procriativa. Esta consciência é, em parte, consequência de uma reacção perante a situação mundial. Actualmente a pressão sócio-cultural reforça o equilíbrio da mulher.

As dificuldades encontradas pela mulher, em tempos passados, eram atribuídas sobretudo aos preconceitos das velhas tradições, pelo motivo de que a sociedade era feita para o homem, tentando este justificar tal facto através do apelo aos esteriotipos habituais sobre a natureza e a função da mulher. A escolha da procriação era-lhe imposta pelo ambiente que a circundava, sendo influenciada 
mais pelas reacções externas do que pelas suas próprias escolhas. $\mathrm{O}$ seu maior dever era a procriação, a qual vinha a representar também a sua principal função.

Muita literatura, que exalta a beleza e a serenidade interior do sentimento materno, aparece, de algum modo, cúmplice, frente à história demográfica, nas notícias sobre os nascimentos, nas relações sociais, etc. Escondida, apresenta-se uma longa história de mulheres ignorantes com escassa consciência, passivas pelo condicionamento, livres quase só no escolher entre resignação e desespero interior, sem oportunidades de fazer uma verdadeira escolha consciente, condigna com a sua própria realidade ${ }^{24}$.

Mas esta imagem deformada da mulher, hoje com as suas novas experiências, é fruto de uma longa caminhada, para se acertar com a livre escolha e se recusarem esquemas impostos. A reprovação que se fazia, considerando a mulher mais sujeita a proteger e tutelar as suas funções (especialmente biológicas) que a sua intrínseca dignidade de ser humano, tem sido, ao menos teoricamente, garantida pela cultura ambiental. $O$ modo, cada vez mais semelhante, segundo o qual se tem expresso o comportamento procriativo da mulher, embora com grande diversidade, regimes, legislações e níveis de vida, tem constituído, nos nossos dias e por toda a parte, um fenómeno decisivamente notável ${ }^{25}$.

Podemos concluir, afirmando que os influxos da cultura ambiental têm sido decisivos, ao exercerem sobre a mulher uma menor constrição na imposição à função procriativa. Esta é agora mais uma escolha sua, e é tanto mais sua quanto mais conhecimentos ela tiver ${ }^{26}$. A sua mais elevada instrução eleva a sua posição, automaticamente esta passa por condições mais desfavoráveis no ambiente onde se insere.

\subsection{Maior possibilidade de outros interesses e satisfações}

Os interesses da mulher são geralmente orientados para a sociabilidade, isto é, para o interesse pelas coisas sociais e pela participação nas mesmas. Deste modo, a sociabilidade tem para a mulher uma correlação muito significativa com a felicidade.

Por obra da instrução, a mulher tende a deixar-se absorver por outras aspirações que, em tempos idos, eram inconcebíveis na sua vida rotineira do dia a dia. A mulher tem da instrução uma avaliação positiva, isto porque esta a emancipa, torna autónoma e independente, eliminando as frustrações da vida de casa, levando- a a participar, juntamente com o homem, na vida social, a exprimir a sua capacidade, de modo a envolvê-la na dinâmica social e nesta tomar participação activa.

Para a mulher menos instruída, as solicitações culturais que a levam a outros interesses e satisfações são bem menores. Quanto mais aumenta o nível de ins- 
trução da mulher, tanto mais aumenta o interesse por outras coisas ${ }^{27}$. As suas opções são ligadas a uma vontade mais forte.

Com mais conhecimentos, a mulher atinge agora, com maior rapidez e percepção, o significado da sua pessoa como ser humano, inteligente, que leva a motivações de poder satisfazer outras aspirações. Passa a não estar motivada somente para o trabalho de casa, ou para a dedicação aos filhos e ao marido. Uma visão mais aberta fá-la descobrir outros ideais, tem agora uma visão mais ampla das coisas, do mundo que a envolve. Torna-se assim notável a sua menor predisposição para a função da procriação que, embora seja importante, não é exclusiva.

O seu interesse, agora mais forte, pode, em parte, ser explicado pela diminuição da timidez, numa maior confiança em si mesma, maior extroversão, orientando, portanto, o comportamento para uma vida mais externa e participativa e para uma realização mais prática e positiva.

\subsection{Atrasa a idade do matrimónio}

Um dos factores determinantes da idade do matrimónio é, sem dúvida, a instrução. Geralmente verifica-se que o prolongamento dos estudos corresponde a um matrimónio tardio. A mulher tende a retardar o matrimónio, enquanto não atinge um certo nível de instrução. Embora o grau de concentração dos matrimónios na idade inferior aos 25 anos tenha tendência a aumentar, no caso de muitas mulheres que estudam verifica-se o contrário. Estas encontram conveniências não só em terminar os estudos, como também, depois destes, em procurarem encontrar trabalho, antes de contrair matrimónio. As razões são óbvias, a maior segurança pessoal é essencial mesmo depois do matrimónio. A situação descrita é bem visível, se consultarmos os anuários de estatística nacionais. $\mathrm{O}$ fenómeno verifica-se, mais ou menos, por todo o lado.

Só a título de exemplo, podemos fornecer alguns dados recolhidos duma pesquisa feita em Itália em 1979, na qual se mostra como a idade média do matrimónio é diferenciada. A mulher, sem qualquer diploma de habilitações, apresenta uma idade média de matrimónio inferior em 3 anos à das licenciadas, de 2 anos inferiores às diplomadas por Escolas Secundárias, de 1-2 anos inferior aquelas que possuíam o nível de escolaridade obrigatória ${ }^{28}$.

A instrução, para algumas mulheres, desacelarou o desenvolvimento comportamental em relação ao matrimónio ${ }^{29}$. Concretamente podemos dizer que a mulher, que estudou e fez carreira, pode decidir com maior autonomia se e quando contrair matrimónio.

Uma pesquisa feita pela DOXA (organismo dedicado à investigação) em 1973 revelava que só $29 \%$ das mulheres entrevistadas declaravam considerar o matrimónio como ideal principal, contra $70 \%$ que aspiravam a um grau de instrução e 
a um trabalho qualificado, acentuando-se este quando se elevava o grau de instrução $0^{30}$.

Por isso, o atraso do matrimónio pela mulher é, em parte, atribuído ao factor tempo que a mulher precisa para terminar os estudos, com sucessivas possibilidades de escolha.

\subsection{Maior número de crises no matrimónio}

Geralmente as crises no matrimónio põem em discussão o homem e a mulher. Daí a dificuldade em fazer uma análise que toque só à mulher. Não se trata de crises imputadas à perda das funções da mulher, como muitas vezes se pensa, mas trata-se de crises de solidariedade que afectam o casal em todos os níveis da vida matrimonial.

No nosso trabalho não tratamos das crises do matrimónio em geral, mas daquelas que, particularmente, atingem a mulher nos confrontos com o marido. Pensamos que a maior crise para a mulher é provocada quando o homem julga a mulher inferior a ele. Com efeito, e se ela, outrora, pensava que era assim, sentindo-se na obrigação de se submeter a ele, hoje praticamente nenhuma o aceita, muito menos aquela que possiu um grau de instrução, e muito menos a que o tiver equiparado ao seu. Esta não reconhece autoridade superior ao marido.

Sabemos que a mulher, muitas vezes, não encontra compreensão e, sobretudo, se tem filhos. Ouvem-se ainda, frequentemente, muitas críticas, por parte da mulher tradicional, contra a concepção moderna de mulher. Esta deve superar ainda muitos obstáculos de ordem material - problema do trabalho extradoméstico que muitas vezes é mal visto pelo marido, problema da instrução, se ela tem um título inferior e por isso problemas de ordem psicológica, oposição do marido -, tentando por vezes criar um equilíbrio, mas que se mostra frágil, entre a vida que faz e a vida que desejaria fazer. A oposição do marido constitui um obstáculo que será difícil de superar, sem que este traga uma desunião. Algumas conclusões de pesquisas que têm estudado as relações do homem com a mulher mostram que, na maioria dos casos, é a mulher a querer o divórcio ou a separação ${ }^{31}$. A atitude da mulher, quanto a esta tomada de decisões, é atribuída, em parte, ao facto de o homem não permitir que seja ela a tomar determinadas posições na família e no matrimónio. Ela quer um homem que aceite as suas ideias, embora diferentes das dele. As crises tornam-se mais intensas para a mulher quando o homem the impõe a sua mentalidade. A mulher exige mais dignidade e não a venda ou troca no matrimónio ${ }^{32}$. $\mathrm{O}$ forte desequilíbrio, entre ambos, leva-os a refugiarem-se numa conflitualidade existente entre ideias contrastantes. As razões entram em crise. A mulher que, por longos séculos, viveu à sombra do marido, considerada somente como esposa «boazinha», hoje rejeita este facto como «valor», mas quer um homem que reconheça a sua personalidade e lhe dê possibilidades de realizar-se, como ele, com todas as suas capacidades. Mas é difícil admitir a paridade de níveis. O homem tem medo de perder o prestígio. 
É preciso considerar não só a personalidade do marido, mas a relação entre personalidades opostas.

No bom sentido, costuma-se querer que uma mulher se case com um homem, geralmente com um nível intelectual, ao menos em aparência, semelhante ao seu. Todavia, a inteligência é uma coisa, mas outra coisa são a personalidade e a educação que a modelaram.

\section{O CONTROLO DA MULHER SOBRE OS ANTICONCEPTIVOS}

Um ulterior factor a considerar e que tem actualmente contribuído, com maior força, para a emancipação da mulher tem sido, sem dúvida, o controlo exercido por ela sobre os anticonceptivos, levando, por assim dizer, a reduzir a função materna, no que respeita aos seus aspectos procriativos e, consequentemente, à diminuição da natalidade. Esta vem a ser decididamente uma escolha sua.

\subsection{Controlo e uso dos anticonceptivos}

Um facto importante das transformações que estamos a examinar consiste em a mulher poder intervir decisivamente por meio do controlo e do uso dos anticonceptivos, na limitação dos nascimentos. Quando de 12 ou 15 filhos, vindos ao mundo, sobreviviam 4 ou 5 , não se falava obviamente no controlo dos nascimentos.

Mas a partir do século XVIII, com o desenvolvimento industrial e melhores condições de vida, seguiu-se um século de grande expansão demográfica, a tal ponto de levar MALTHUS a que, pelo fim do século (1798), escrevesse o seu famoso livro sobre a população, no qual indicava a necessidade de se recorrer à limitação dos nascimentos. $O$ que muda de figura, nas suas perspectivas e naquelas que estamos a examinar, é que a sua medicina era muito especial e não aceite pela maioria da população. É que o estabelecer freios, entre os quais a castidade e o atraso do matrimónio ${ }^{33}$, não era razão aceitável e, por isso, não dava resultado.

O emprego de práticas para evitar a fecundidade não entrava na sua concepção e, por isso, também não entra como elemento específico do nosso trabalho. $\mathrm{O}$ método que ele propunha era aplicável ao homem e à mulher $\mathrm{r}^{34} \mathrm{e}$ nós tratamos daqueles que são dominados pela mulher em particular.

O controlo dos anticonceptivos exercido pela mulher é um acontecimento recente, embora já J. STUART MILL, em 1869, defendesse que uma forte diminuição da fecundidade se esperava da emancipação feminina ${ }^{35}$.

Em 1888, WILHELM MENSINGA inventou o diafragma ${ }^{36}$, o primeiro aceite pela medicina mas com algumas inconveniências pois, a intervenção ginecológica, não era muito usada pela mulher deste tempo, muito menos para tal fim. 
Só sensivelmente a partir do ano 1950, com o aparecimento da pílula, a mulher pode ser senhora de controlar o número de filhos que deseja.

$\mathrm{O}$ controlo dos anticonceptivos confere à mulher um papel valorizador, pois não só é ela que escolhe, mas é ela que prevê a própria fecundação e a controla. $\mathrm{Na}$ escolha de um contraceptivo é o parecer da mulher que, apesar de tudo, deverá ser decisivo, até porque seria ela a passar pelos maiores problemas de uma gravidez não desejada. Daí que o controlo da fecundidade, tornado possível à mulher, seja um grande acontecimento na sua vida.

Não esquecer que falamos em sentido geral, pois tal evolução, na aceitação e difusão de meios anticoncepcionais utilizados, encontra grande facilidade nalgumas partes, mas noutras a cultura tradicional (política, possibilidades financeiras, liberdade para a mulher) que, em certos casos, se mantém, encontra ainda grande resistência.

\subsection{A mulher com maior capacidade de domínio}

A mulher, com mais capacidade de domínio, vem sendo analisada por nós sob dois aspectos: o primeiro a ser considerado é que a vinda dos anticonceptivos exigiu à mulher maior conhecimento da sua fisiologia, dos seus processos biológicos que se realizam segundo determinadas exigências do organismo. Só depois deste conhecimento de si mesma e do seu corpo, do seu funcionamento, ela pode ter domínio sobre os anticonceptivos e utilizá-los conscientemente, sem também se deixar manipular por eles. É importante, para a mulher, saber regular o uso dos anticonceptivos, segundo o seu próprio organismo.

Um segundo aspecto que queremos sublinhar é o facto de ser ela própria, mulher como pessoa potenciada, que escolhe e regula o uso dos anticonceptivos.

Estão claros, na nossa interpretação, os dois conceitos: conhecimento da sua fisiologia e dos seus processos biológicos, bem como a utilização e o domínio dos anticonceptivos. Embora independentes um do outro, contribuem, juntamente, para um mesmo objectivo que é, em primeiro lugar, a libertação da mulher de ideias tradicionais e, em segundo, para a diminuição, ou seja, o controlo da natalidade.

Assim, o «birth control», o uso de contraceptivos, em termos de "papéis», constitui para a mulher uma mudança irreversível. Pode, inclusive, afirmar-se: «graças aos contraceptivos, tudo isto se tem devido ao nosso domínio sobre eles. É com toda a certeza um dos maiores progressos do mundo moderno ${ }^{37}$ ». Podemos dizer que, a uma filosofia da aceitação, se substitui uma filosofia de escolha.

Assim, a mulher, sempre habituada a analisar a sua vida em termos de coerção, tem hoje um poder verdadeiramente considerável sobre si mesma. O controlo e o domínio dos anticonceptivos, agora sem apanágio, levou-a a substituir uma gama de tabus, mitos e preconceitos que a situavam a um nível inferior ao homem. A remoção destes tabus libertou a mulher da sua prisão de ignorância e de insatisfação no campo sexual. Não vai ainda muito longe o tempo em que o 
amor físico era um «dever», uma obrigação, como vimos já acima, mas hoje tornou-se um «prazer» ${ }^{38}$, graças à capacidade de domínio que a mulher atingiu com o controlo dos anticonceptivos.

A maioria das mulheres desconhecia-se, como desconhecia o seu próprio corpo, as suas possibilidades e, por isso, ignoravam as suas capacidades, aceitando a passividade que se thes impunha na relação sexual. A ignorância era, portanto, aliada incondicional da exploração de que eram vítimas. Em parte porque a educação sexual se limitava , basicamente, à informação sobre reprodução e não reprodução, sem analisar o valor, em si mesmo, do que significava concretamente para a mulher.

$\mathrm{Se}$, em tempos passados, certos factores de dominação masculina determinavam os comportamentos da mulher em relação à procriação, nos dias de hoje deu-se uma revolução em tais comportamentos, pelo que FEDERICI fala da passagem de uma fecundidade «natural» a uma fecundidade «controlada» ${ }^{39}$.

Aqui o problema não se põe em termos de usar ou não os contraceptivos, mas trata-se, sobretudo, da possibilidade que estes deram à mulher, de ser mãe todas as vezes que quer e quando ela própria quiser. Se algumas mulheres têm quinze filhos e outras têm só dois ou três, não é este privilégio de não ter filhos o último fim, mas é o de ter só os que conscientemente acha que deve. Se a literatura que circula tem convidado as mães e, em particular, as da Europa à procriação, ou seja à produção de filhos, elas respondem que o tipo de responsabilidade social que sentem não é o de ajustar o nível de salário, mas de destruir todo o mecanismo, para conceberem todos os filhos que querem e só as vezes que querem ${ }^{40}$.

Em conclusão: a fecundidade não é somente uma coerção, uma repressão, mas um privilégio, que pode tornar-se poder, na medida em que, através da capacidade de domínio, à mulher pertence decidir de ser ou não fecunda ${ }^{41}$. O controlo da fecundidade, com os meios que se vão tornando disponíveis, sob o domínio da mulher, influenciam de modo considerável na natalidade. A fertilidade é um poder que o homem não pode conquistar, já que este pertence à mulher.

\subsection{Várias técnicas anticoncepcionais}

Os sistemas anticoncepcionais disponíveis são muitos, pelo que cada mulher é condicionada, por vários factores, na escolha de usar um ou outro. Condicionam-na a educação recebida, as influências ambientais, as experiências pessoais, uma determinada concepção de vida, etc. Os mais conhecidos no mercado e utilizados pela mulher são: a pílula, o dispositivo uterino, espermicidas vaginais, etc. Existem também os métodos naturais, a que faremos uma breve referência, pois estão igualmente ao alcance da mulher. 


\subsubsection{Métodos naturais}

Os métodos naturais são assim definidos, enquanto a sua aplicação se baseia na observação e na investigação dos fenómenos que caracterizam normalmente o ciclo menstrual. Portanto, estes métodos utilizados pela mulher são determinados no organismo, procurando individualizar o período ovulatório, ou seja o período fecundo da mulher, de modo que ela possa, naqueles momentos, evitar a fecundação.

Os métodos naturais admitem portanto: a abstinência periódica nos dias fecundos do ciclo feminino ${ }^{42}$. As modalidades que caracterizam este período são: as variações do muco cervical, variações da temperatura basal, alguns sinais objectivos e sintomas tais como: dores no ventre, sensação de peso, etc. Os métodos naturais são aconselhados, de forma conjugada, entre si, para um aumento de segurança.

\subsubsection{Métodos físicos ou mecânicos}

Os métodos físicos podem ser considerados como barreiras que se põem entre os espermatoz6ides e a célula do ovo. Actualmente estes meios são: diafragma, formado por uma membrana de borracha ligeira, mas resistente que se introduz na vagina. $\mathrm{O}$ dispositivo intra-uterino (DIU) ou aspiral. Existem vários modelos e com vários aspectos, são constituídos de material plástico associado com substâncias de progesterona. A diferença do anterior é que este é inserido por um ginecologista no interior da cavidade uterina. $O$ dispositivo obstacula a penetração espermática, alterando a vitalidade do espermatozóide e modificando as células do endométrio, de modo que uma célula - ovo fecundado, já em actividade, não possa aninhar-se, pelo que uma gravidez inicial é interrompida.

\subsubsection{Métodos químicos}

Os métodos químicos têm uma acção antifecundativa. $\mathrm{O}$ meio anticoncepcional químico mais usado é a pílula estraprogestínica. Existem vários tipos, que são aconselháveis segundo os casos. A pílula é praticamente hoje o meio mais usado, pela facilidade que oferece. Além disso, a sua segurança é de $99 \%$ e é bem tolerada. Geralmente o médico especialista é consultado na escolha, bem como na continuação do tempo de a usar. Porém, não raros são os casos em que a mulher a usa com os conselhos de amigas, publicidade, etc. Embora com contraindicações, é realmente, segundo os cientistas, o contraceptivo mais recomendado e mais usado pela mulher, além do preservativo intra-uterino (cfr. tabela III, em apêndice).

Existem também o creme e os óvulos espermicidas que têm a função de matar o espermatozóide ainda na vagina, mas não são muito usados. 


\subsubsection{Métodos cirúrgicos}

Estes métodos, também chamados métodos esterelizadores, são aplicáveis tanto na mulher como no homem. No homem é a chamada vasectomia, ou seja o fecho dos dois canais que conduzem os espermatozóides dos testículos à uretra. $\mathrm{Na}$ mulher consiste na ligação das trompas. Estas são ligadas, cortadas ou interrompidas mediante dispositivos particulares. Os espermatozóides não podem alcançar o ovo e fecundá-lo.

É um dos métodos que oferece mais segurança, mas o factor negativo consiste em não permitir a reversibilidade. E, por isso, deve ser considerado uma solução definitiva.

Por fim, queremos sublinhar que o nosso interesse principal neste trabalho não era dar um estudo completo de tais métodos, mas achámos por bem dar um pequeno esquema, que sirva para completar a descrição e intensificar a respectiva utilidade, na sua utilização pela mulher. Indicamos por isso as fontes de que nos servimos para a verificação de um estudo mais completo ${ }^{43}$.

\subsection{Igualdade entre o homem e a mulher}

Tudo aquilo que é do outro deve ser também meu. Um homem será mais homem na medida em que tornar a mulher mais mulher e vice-versa. Só dois seres, unicamente diferentes, podem potenciar as respectivas unicidades. Mutualidade, mais do que igualdade, parece ser o atributo que define a relação homem/mulher, baseada numa comparticipação das próprias identidades. As diferenças podem ser valorizadas, pois, não se verificando comportamentos proibidos ou dominados; a expressão, segundo o desejo de cada um, leva à igualdade de poderes na diversidade da pessoa.

Com razão LEMAIRE escreve: «As posições que tendem à igualdade de sexos facilitam uma recíproca identificação e favorecem a comunicação e o diálogo. Mas, no plano sexual, quando o homem e a mulher realizam esta igualdade encontram o dever de organizar a ligação hetero-sexual, que exige a valorização das diferenças entre os sexos» ${ }^{44}$. Os contraceptivos foram, assim, um dos instrumentos mais fortes que tornaram a mulher mais igual ao homem.

Uma maior igualdade exige uma nova consciência da procriação, exige uma consciente revisão do sentido e do valor da relação sexual. A qualidade de vida sexual é, neste contexto, o parâmetro da capacidade em estabelecer uma relação autenticamente paritária. Deste modo, a possibilidade e a facilidade da prática anticonceptiva constitui a plataforma de uma libertação da mulher, bem como das suas decisões e escolhas procriativas.

Esta paridade tem muita influência sobre a natalidade, enquanto são mais respeitados os rítmos biológicos, psicológicos e sociológicos da mulher. Por isso, derivam da natalidade influxos que se substancializam na diminuição das concepções e sua consequência nos nascimentos. Entram aqui também os con- 
ceitos desenvolvidos em relação à mulher sobre a autonomia, a menor disponibilidade, quer psicológica quer materialmente, como espusemos nos parágrafos precedentes.

\section{CONCLUSÃO GERAL}

Ao terminar esta série de considerações, é necessário chegarmos a algumas considerações concretas. No estudo e na descrição deste trabalho pudemos constatar que existe uma multiplicidade e variedade de factores que actuam, de certo modo isolados mas também de modo interdependente, sobre a natalidade. Portanto, não devemos reconhecer, nos processos observados, o efeito de uma simultaneidade de causas, mas o efeito de interrelações entre vários factores. Assim, podemos concluir que os factores por nós analisados - trabalho extradoméstico, instrução e controlo da mulher sobre os anticonceptivos - constituem três variáveis que serviram de base na mudança do «status» e do papel da mulher na família e na sociedade. Mas estes, por sua vez, influenciam directamente e estão interrelacionados, de modo visível e determinante, na natalidade.

Aparece-nos deste modo um novo modelo cultural da concepção típica da família. Seria difícil explicar, de modo satisfatório, as características evolutivas através das relações entre fecundidade e os factores por nós considerados, sem fazermos uma breve referência ao novo tipo de família.

O tipo fundamental de família, na formação social contemporânea, é a família nuclear isolada, que consiste no grupo formado por um homem, uma mulher e os filhos, socialmente reconhecidos ${ }^{45}$. Quanto à composição desta família, verifica-se uma redução do número de membros em relação à família alargada; a família tem normalmente os dois cônjuges, um ou dois filhos e raramente mais de três. Verifica-se também uma colocação no território, mais ou menos longe da família de origem dos dois cônjuges, criando-se um novo núcleo, reduzido ao essencial. Por outro lado, verifica-se uma redução das funções, exclusividade ou redimensionamento destas ${ }^{46}$.

A função da reprodução é limitada pela tendência à redução do número de filhos, quer efectuada segundo o princípio da paternidade e maternidade responsável, quer segundo as indicações da Igreja, ou ainda em modos diferentes ${ }^{47}$.

Aparece, assim, uma nova concepção da relação mulher/maternidade. Se esta, hoje, começa a ser posta em causa por muitas mulheres, como ideal exclusivo de realização de si mesma, não é que a mulher se esteja a tornar egoísta ou tenha menos respeito pela vida. Podem influenciá-la, sem dúvida, componentes deste género, mas é necessário termos em conta as condições nas quais a maternidade se realiza ${ }^{48}$.

Portanto, a maternidade para a mulher pode assumir uma série de significados, em relação à importância cultural, psicológica e espiritual. A moderna perspectiva da mulher superou a concepção fatalística do destino exclusivo à materni- 
dade e isto foi muito importante para a mulher. Sabemos quão discutível é esta realidade da identificação da mulher com a maternidade, a transformação do significado da procriação e o valor desta, a ponto de ser indicada como um fim primário da união sexual (e no ensinamento cristão como única justificação da mesma união).

A maternidade constitui um facto positivo para a mulher, mas quando é querida e procurada como «experiência» pessoal, como livre gestão de si, das próprias potencialidades físicas e psicológicas. Aqui não está em jogo o serviço que a mãe desenvolve em relação ao filho, mas exactamente o contrário: é o filho que serve a pesquisa existencial da mãe. Processa-se, deste modo, uma reviravolta naquela concepção de maternidade, que passa a ser encarada como um serviço de protecção da mulher em relação ao outro. A mulher hoje não é - e não se sente tal -, sobretudo enquanto mãe, potencial ou de facto. $E$ isto principalmente porque ela mesma é pessoa humana, assinalada mas não determinada pelo sexo biológico.

A maternidade, de qualquer modo, assume para a mulher uma importância que, querida ou rejeitada - qualquer que seja a sua decisão — já não é vista como anteriormente. Assim, destes dados não só culturais - tomados por grande parte das mulheres - e psicólogos e da sua correlação, sai a exigência de uma nova consciência sobre a maternidade, que se quer rejeitar como facto e se quer fruto de uma escolha livre e consciente. A maternidade apareceu, sempre, como uma novidade e, para certos aspectos, como um progresso, em relação ao passado.

A nova concepção da família e da maternidade levam a uma aceitação da planificação familiar. Geralmente reconhece-se o controlo dos nascimentos como uma necessidade válida para todos. «Procriar, por isso, o menos que se puder». Este é o slogan aceite em todo o mundo ocidental e proposto ao Terceiro Mundo (embora se deva atender à sobrevivência da espécie humana). O facto é que ainda não se chegou a uma conclusão, do modo como actuar na planificação familiar. Discute-se como conduzir uma política oficial de planificação familiar, como fazê-lo de modo mais eficaz. Além da planificação familiar, é preciso incrementar uma política de controlo demográfico ${ }^{49}$.

As investigações, orientadas de modo a individualizar um método simples, seguro, de fácil emprego, aceite e reconhecido por todos, têm sido encorajadas pelas organizações nacionais ou internacionais que se ocupam da planificação familiar. Por exemplo, a O.M.S. (Organização Mundial de Saúde) tem dado prioridade a tais estudos, no âmbito do Programa Especial de Investigação e Desenvolvimento, isto é, à investigação na reprodução humana. Mas todos estes esforços, até hoje, ainda não descobriram um método que seja seguro e adoptado por toda a mulher, sem outras consequências. Os progressos, neste campo, têm sido 
visíveis, sobretudo o esforço por criar uma alteração mais fácil, mais rápida, mais segura e aceite universalmente.

Para a mulher, a aceitação e o reconhecimento da planificação familiar são determinados pelo seu «status» e papel.

A gradual aceitação do controlo dos nascimentos deve ser explicada à luz da evolução geral da mentalidade e adaptação da população. As modificações nos sentimentos religiosos e na aceitação da moral prevalecente, as mudanças nas relações entre o homem e a mulher, a formação de uma consciência política entre meios rurais, industriais e urbanos, são algumas das muitas exigências necessárias para a compreensão da política sobre planificação familiar, em termos de procriação.

Como resultado, temos a diminuição da natalidade. A baixa fecundidade, como vimos, relaciona-se com o «status» e o papel da mulher. A fecundidade diminui quando a mulher se ocupa de actividades extra-familiares, especialmente, como ficou exposto, se o trabalho é efectuado fora da residência. As provas que existem actualmente indicam, no que se refere ao trablho da mulher, que este tem sobre a fecundidade uma influência muito mais importante que outras actividades sociais. Por outro lado, vimos também que o maior grau de instrução proprociona à mulher um maior acesso a informações, dando-lhe possibilidades mais amplas e interesses que não se relacionam especificamente com a família, favorecendo-lhe o desenvolvimento e aumentando a abertura a outros relacionamentos. Como também a invenção e a produção de contraceptivos favorecem, evidentemente, o controlo da fecundidade, limitando portanto a extensão da família. Este terceiro factor, como dissemos, é actualmente mais significativo que os anteriores, é aquele que contribui, nos dias de hoje, para uma maior aceitação, pela mulher, da planificação familiar.

Estas hipóteses destacam certos requisitos estruturais da família, necessários para que seja eficaz o controlo da fecundação e se mantenha a família em dimensões reduzidas.

As explicações sobre o declínio da fecundidade, que se verifica praticamente em todo o mundo industrializado, concentram-se portanto nesta mudança de «status» e papel da mulher, os quais, por seu lado, deram origem, por norma, a famílias pequenas, tendo influenciado, directa ou indirectamente, sobre a redução da natalidade. 


\section{NOTAS}

* O trabalho que agora se publica,revisto e ligeiramente remodelado, foi inicialmente apresentado no Seminário dirigido pelo Professor Pedro Calderan Beltrão, na Universidade Gregoriana em Roma, no ano lectivo de 1884-1985.

1. FEDERICI, N., Procreazione, famiglia, lavoro della donna, Ed. Loescher Università, Torino, 1984; KAREN, O. M., The Status of Women, Ed. Rockefller Foundation, 1984, p. 2-3.

2. FICTHER., Sociologia fondamentale, Ed. Querino, 1963, p. 181-182.

3. Tais conclusões podem ser tiradas da bibliografia geral utilizada, onde mais ou menos todos os autores tratam do assunto, mas não entrando especificamente na temática do nosso trabalho pois, como dissemos, nós queremos analisar como este «status» e papel influenciam sobre a natalidade e não as transformações que têm sofrido.

4. KAREN, O., M., The status of women, op. cit., p. 12-13.

5. FEDERICI, N., Procreazione, famiglia, lavoro della donna, op. cit., p. 81-83.

6. BELTRÃO, P. C., Sociologia della famiglia contemporanea, Ed. P.U.G. Roma, 1977, p. 224.

7. Cada nação, com suas dinâmicas, interpreta e dá significados diferentes e respostas à necessidade ou não de uma alta ou baixa fecundidade, mas tal facto depende de circunstâncias culturais que justificam suas razões numas sociedades com uma visão e moutras com outra. Sabemos quão diferentes são os interesses dos vários países. Se por acaso confrontamos um país industrializado com um subdesenvolvido, os interesses para a procriação destacam- se bem um do outro. Cfr. KAREN, O. M., The status of Women, op. cit. p. 43-47.

8. BELTRÃO, P. C., Sociologia della famiglia contemporanea, op. cit., p. 86, SULLEROT, E., La donna e il lavoro. Storia e sociologia del lavoro femminile, Ed. Etas Compass, Milano, 1969, p. 348.

9. Entendemos por trabalho extradoméstico aquele exercido pela mulher fora do âmbito familiar e donde a própria mulher tira para si um rendimento monetário (BELTRÃO, P. C., Sociologia della famiglia comtemporanea, op. cit., p. 86-102).

10. FEDERICI, N., Procreazione, famiglia e lavoro della donna, op. cit., p. 118-123.

11. Ibidem, p. 110-138.

12. Os resultados de algumas pesquisas, feitas a nível de fecundidade e trabalho extradoméstico, justificam a afirmação. FEDERICI dá, no seu livro Procreazione, famiglia e lavoro della donna (p. 140-157), alguns dados a nível europeu e a nível da Itália, que nos mostram bem a evidência de tal facto.

13. PECHADRE, L., e ROUDY, Y., Il Sucesso della donna, Ed. Sansoni, Firenze, 1975, p. 130.

14. KAREN, O. M., The status of women, op. cit., p. 67-68.

15. MYRDAL, A., e KLEIN, V., I due ruoli della donna, Ed. Armando Armando, Roma, 1973, p. 63 ss.

16. CAZORA, G. R., Status sociale della donna, Ed. De Luca, vol. I, Roma, 1978, p. $109-110$.

17. PIERRE, B., "La Politique familiale", Revue de L'Institut International d'Études Sociales, vol. 8, n. ${ }^{\circ}$, 1983, p. 445-446; MYRDAL E KLEIN., Idue ruoli della donna, op. cit., p. 122. 
18. FEDERICI N., Procreazione, famiglia, lavoro della donna, op. cit., p. 76.

19. BELTRÃO, P. C., Sociologia della famiglia contemporanea, op. cit.

20. ISTAT, Indagine sulle strutture e il comportamento familiare, foglio 41 , anno $\mathrm{V}, \mathrm{n} .{ }^{\circ} 5$, Luglio, 1984. Pelos dados apresentados também por Federici, os quais transcrevemos, podemos concluir que a instrução determina a escolha da procriação. Entre doméstica e aquela com trabalho extradoméstico a tempo pleno e com paridade de instrução, temos 3,2 domésticas contra 2,4 com trabalho extradoméstico. Para aquelas sem qualquer título de 2,2 a 1,8 para aquelas com diploma elementar, de 1,8 a 1,3 para as de diploma médio. Cfr. FEDERICI, N., Procreazione, famiglia, lavore della donna, op. cit., p. 156. FEDERICI mostra ainda que o número médio de filhos - a paridade de duração matrimonial - de 2,5 por cada mulher sem algum título de estudo contra 1,7 para aquelas com instrução médio-superior. Enquanto as analfabetas e semianalfabetas $57 \%$ tinham em média 3 ou mais filhos, entre as mulheres com instrução médio-superior a percentagem descia a $11 \%$ (op. cit., p. 63).

21. AA. VV., Essere madre oggi, Ed. La Scuola, Brescia, 1980, p.27.

22. FRIEDAN, B., La seconda fase, Ed. Comunità, Milano, 1982, passim.

23. GAIOTTI, P. B., e CECILIA, N., La Questione Femminile, Ed. Le Monnier, Firenze, 1982, p. 77.

24. Justamente se rejeita uma procriação como destino, como um serviço à conservação da espécie e muito menos às exigências do marido. Cfr. MICHELL, J., La condizione della donna, Ed. Einaudi, Torino, 1972, p. 162-163. Portanto mais atenta à dimensão qualitativa que quantitativa da fecundidade, pois que a «procriação não pode ser a finalidade primária do matrimónio e das relações sexuais» (BELTRÃO, P. C., Sociologia della famiglia contemporanea, op. cit., p. 153).

25. SULLEROT, E. (a cura di), Il fenomeno donna, Ed. Sansoni, Firenze, 1980, p. 478.

26. CAZORA, G. R., Essere donna, Ed. Rizzoli, Milano, 1980, p. 19.

27. CAZORA, G. R., Essere donna, op. cit., passim.

28. FEDERICI, N., Procreazione, famiglia, lavoro della donna, op. cit., p. 64.

29. Ibidem, p. 145-147. Não raras são aquelas que deixam os estudos para contrair matrimónio, pensando continuar o ritmo depois de algum tempo, se não mesmo abandoná-los. Certo é que a vida se transforma, o marido acha que não vale a pena, depois os filhos, etc. Ela acaba por perder as esperanças. Constituindo, assim, o matrimónio e os filhos uma desvantagem, na sua carreira, e portanto na assunção de uma profissão, ao menos qualificada, à qual ela aspirava.

30. AA. VV., Essere madre oggi, Ed. La Scuola, Brescia, 1980, p. 17.

31. AA. VV., Problemi e modelli di vita familiare, Ed. Vita e Pensiero, Milano, 1980, p. 64-88.

32. SULLEROT, E., La donna e il lavoro, Ed. Bompiani, Milano, 1977, p. 188-123.

33. BELTRÃO, P. C., Teorie demografiche, Dispensa, 1985/86, Cap. I, p. 5-20.

34. A verdadeira propaganda do uso dos anticonceptivos só com F. PLACE, a partir de 1822 , se espalhou. Este opunha-se, portanto, à prática contraceptiva proposta por MALTHUS: «moral restraint» (Cfr. BELTRÃO, P. C., Teorie demografique, op. cit., cap. VII, p. 1-6). Daí que a diminuição da fecundidade se verificasse com o abandono do método maltusiano, em favor do método neo-maltusiano: o uso dos anticonceptivos.

35. BELTRÃO, P. C., Teorie demografiche, op. cit., cap. III, p. 21. 
36. Ibidem, cap. VI, p. 14.

37. TANISLAS, L., La limitación de los nacimientos, Ed. Helder Barcelona, 1962, p. 33.

38. PECHADRE, L. e RUODY, Y., Il successo della donna, op. cit., p. 207.

39. FEDERICI, N., Procreazione, famiglia e lavoro della donna, op. cit., p. 17-18.

40. AA. VV., Il femminismo e lotta di classe in Itália, (a cura di) FRABOTTA, B. M., Ed. Savelli, Roma, 1975, p. 81; FEDERICI, N., Procreazione, famiglia e lavoro della donna, op. cit., p. 17.

41. SULLEROT E., Il fenomeno donna, op. cit., p. 477.

42. BELTRÃO, P. C., Teorie demografiche, op. cit., p. 10.

43. BELTRÃO, P. C., Teorie demografiche, op. cit., cap. III-IV; BALLIELO, S., Una donna, un uomo mille perchè, Ed. Paoline, Torino, 1985, p. 25-29; BOMBELLI, F. e CARUGNO R., Educazione ai métodi naturali, Ed. CISF (Centro Internazionale studi Famiglia), Milano, 1983, p. 30-71; FEDERICI, N., Procreazione, famiglia e lavoro della donna, op. cit., p. 66-67.

44. LEMAIRE, J. G., Le terapie di coppia, Ed. cittadella, Assisi, 1975, p. 48.

45. BELTRÃO, P. C., Sociologia della famiglia contemporanea, op. cit., p. 18.

46. O número reduzido de filhos isola o casal, pelo que a crise entre os dois é a crise da família, a qual não encontra na "presença» de outros uma ajuda à interacção e integração e a estabilidade da própria família (PARSONS, T. e BALES, R., Famiglia e socializzazione, Ed. Mondadori, Milano, 1974, p. 35-135).

47. BELTRÃO, P. C., Sociologia della famiglia contemporanea, op. cit., p. 55-72. De facto, a nova situação médico-higiénica põe a família moderna na condição de satisfazer a função de reprodução somente com dois ou três filhos e não, como na família patriarcal, numa média de 6 a 8 filhos.

48. BELTRÃO, P. C., Sociologia della famiglia contemporanea, op. cit., p. 145.

49. BELTRÃO, P. C., Sociologia della famiglia contemporanea, op. cit., p. 145.

\section{BIBLIOGRAFIA}

AA. VV., 1978, Essere donna oggi, Ed. La scuola, Brescia.

—, 1978, Essere madre oggi, Ed. La Scuola, Brescia, 1980.

-, 1978, Verso una società con la donna, Ed. UECI, Città Nuova, Roma, 1981.

-, 1978, Problemi e modelli di vita familiare, Ed. Vita e Pensiere, Milano, 1980, p. 287.

AVANZINI, B. B. et al., Problemi e modelli di vita familiare, Milano, Ed. Vita e Pensiero, 1980.

BALES, R. F., Famiglia e socializzazione, Ed. Mondadori, Milano, 1974.

BALLIELO, S., Una donna, un uomo mille perchè, Ed. Paoline, Milano, 1985.

BELTRÃO, P. C., Sociologia della famiglia contemporanea, Ed. PUG, Roma, 1977. 
BELLENZIER, M. T., Donna e famiglia realtà a confronto, Ed. AVE, Roma, 1977.

-, Questino femminile da dove verso dove, Ed. Paoline, Roma, 1983.

BLANCHET, D. e BLUM, A., "Population", Revue d'Études Dèmographiques, n. ${ }^{\circ} 2$, mars-avril, 1984, p. 281-293.

BOMBELI, F., e CARUGNO, R., Educatione ai metodi natureli, Milano, Ed. CISF., 1983.

CAZORA, G. R., Status sociale della donna, Ed. De Luca, vol. I, Roma, 1978.

—, Essere donna oggi, Ed. Rizzoli, Milano, 1980.

CAMPANINI, G. et al., Essere madre oggi, Brescia, Ed. La Scuola, 1980.

-, et al., Essere donna oggi, Brescia, Ed. La Scuola, 1978.

FEDERICI, N., Procreazione, famiglia, lavoro della donna, Ed. Loescher Università, Torino, 1984.

FERDINANDO, B.E., Educazione ai métodi naturali (a cura di), CISF, Milano, 1983.

FICTHER, Sociologia Fondamental, Ed. Querino, 1963.

FREEDMAN, R., DAVIS, K. e BLAKE, J., Factores sociológicos de la fecundidad, Ed. Centro Latino Americano de Demografia, México, 1967.

FRIEDAN, B., La seconda fase, Ed. Comunita, Milano, 1982.

GAIOTTI, P. B., e CECILIA, N., La questione femminile, Ed. Le Monnier, Firenze, 1982.

ISTAT, Indagine sulle struture e il comportamento familiar, foglio 41, anno V, 1984.

KAREN, O. M., The status of women, Ed. The Rockefeller Foundation, 1984.

LEMAIRE, J. G., Le terapie di coppia, Ed. Cittadella, Assisi, 1975.

MARTINI, M. E. et al., Verso una società con la donna, Roma, Ed. VECI, 1981.

MICHELL, A., Activitè professionnelle de la femme et vie conjugal, Ed. Centre National de la Recherche Scientifique, Paris, 1974.

MITCHELL, J., La condizione della donna, Ed. Einaudi, Torino, 1972.

MYRDAL, A., e KLEIN, V., I due ruoli della donna, Ed. Armando Armando, Roma, 1973.

PARSONS T., Famiglia e socializzazione, Ed. Mondadori, Milano, 1974.

PECHADRE, L., Il successo della donna, Ed. Sansoni, Firenze, 1975.

PIERRE, B., "La Politique Familiale", Revue de l'Institut International d'etudes sociale, Gèneve, 1983.

STANISLAS, L., La Limitación de los nascimientos, Ed. Biblioteca Herder, Barcelona, 1962.

SULLEROT, E., Il fenomeno donna, Ed. Sansoni, Firenze, 1980.

—, La donna e il lavoro, Ed. Bompiani, Milano, 1977. 


\title{
ANEXO
}

\author{
QUADRO I
}

Variáveis que afectam a fecundidade

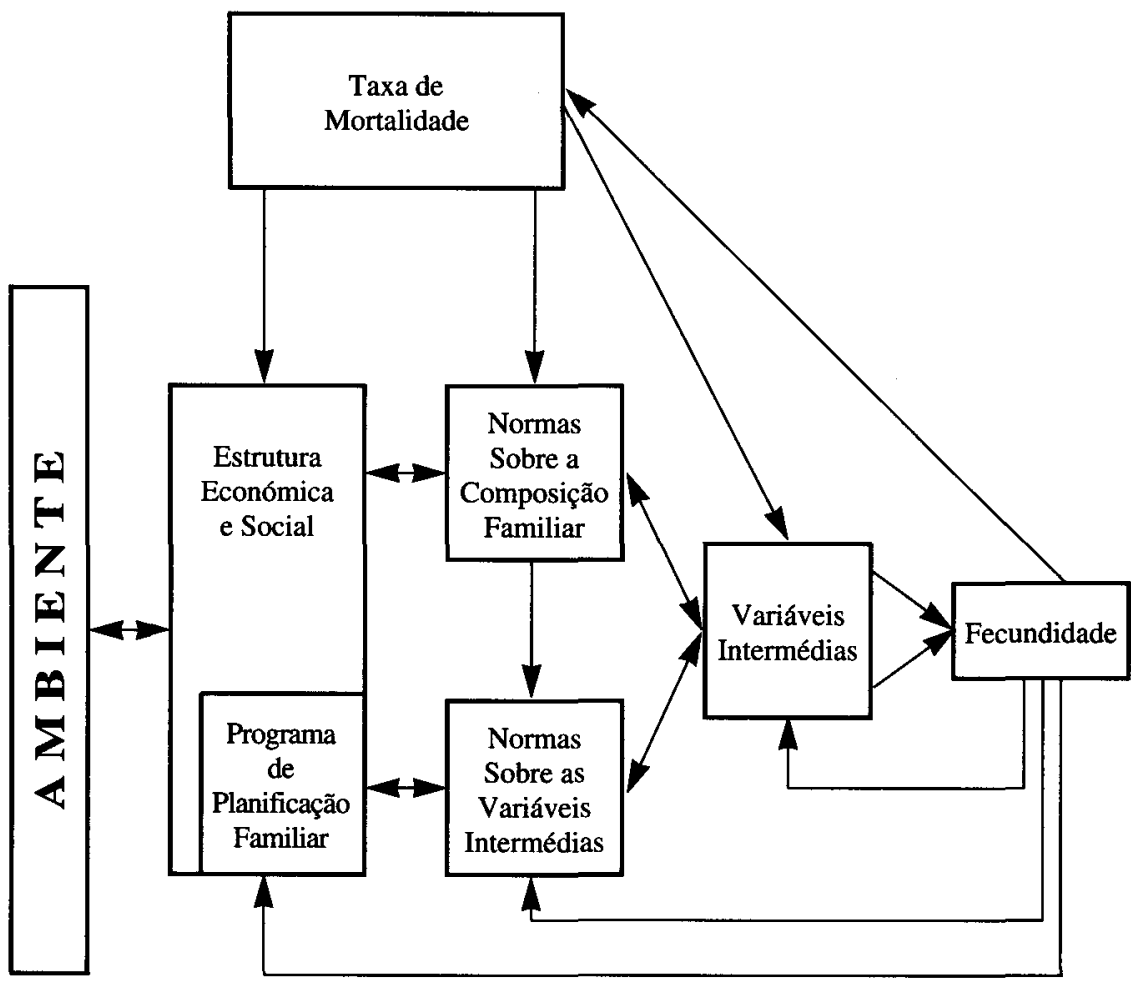

FONTE: FREEDAM, R., The sociology of human fertility, Ed. Irvington Publishers, New York, 1975, p. 283; FREEDMAN, R., KINGSLEY, D., e JUDITH, B., Factores sociológicos della fecundidade, Ed. Centro Latino Americano de Demografia, México, 1967, p. 201. 
QUADRO II

Possiveis modelos interpretativos das tendências demográficas

\begin{tabular}{|c|c|c|c|c|}
\hline \multirow{2}{*}{$\begin{array}{l}\text { NÍVEL DE } \\
\text { RACIOCÍNIO } \\
\text { E AGREGAÇÃO } \\
\text { EMPÍRICA }\end{array}$} & \multicolumn{2}{|c|}{$\begin{array}{l}\text { FENÓMENOS A EXPLICAR } \\
\text { (RESULTANTES) }\end{array}$} & \multicolumn{2}{|c|}{$\begin{array}{l}\text { VARIÁVEIS EXPLICATIVAS } \\
\text { (DETERMINANTES) } \\
\text { SOCIEDADES }\end{array}$} \\
\hline & $\begin{array}{c}\text { EFEITOS } \\
\text { DEMOGRÁFICOS }\end{array}$ & DEMOGRÁFICA & CULTURA & ESTRUTURA SOCIAL \\
\hline $\begin{array}{l}\text { NÍVEL «MACRO» } \\
\text { (POPULAÇÃO } \\
\text { TOTAL/SOCIEDADE) }\end{array}$ & $\begin{array}{l}\text { - N. }{ }^{\circ} \text { de Nascimentos } \\
\text { - Taxas genéricas e espe- } \\
\text { cíficas de fecundidade } \\
\text { - Taxa bruta de reprodução } \\
\text { - Taxa líquida de reprodu- } \\
\text { ção } \\
\text { - N. }{ }^{\circ} \text { médio de filhos por } \\
\text { família } \\
\end{array}$ & $\left.\begin{array}{l}\text { - Nupcialidade } \\
\text { — Fecundidade } \\
\text { — Divorcialidade } \\
\text { — Mortalidade }\end{array}\right\}$ & $\begin{array}{l}\text { Sistema ou mudança de: } \\
\text { - Valores } \\
\text { - Normas } \\
\text { - Leis } \\
\text { - N.o de filhos ideal }\end{array}$ & $\begin{array}{l}\text { Estrutura e mudança da: } \\
\text { - Sociedade } \\
\text { - Economia } \\
\text { - Política }\end{array}$ \\
\hline $\begin{array}{l}\text { NIIVEL «MÉDIO» } \\
\text { (POPULAÇÕES } \\
\text { PARCIAIS } \\
\text { HOMOGÉNIAS) }\end{array}$ & $\begin{array}{l}\text { - } \mathrm{N}^{\circ} \text { médio de filhos por } \\
\text { família e ciclo familiar }\end{array}$ & $\left.\mid \begin{array}{l}\text { - Idade ao Matri- } \\
\text { mónio } \\
\text { - Fecundidade } \\
\text { - Divorcialidade } \\
\text { - Mortalidade }\end{array}\right\}$ & $\begin{array}{l}\text { - Aspirações } \\
\text { - Aspectativas } \\
\text { - Prestígio social } \\
\text { - Identificação } \\
\text { - Instrução }\end{array}$ & $\begin{array}{l}\text { - Relações sociais } \\
\text { - Económicas e políticas } \\
\text { - Grupos de riferimento } \\
\text { - Sistema parentela }\end{array}$ \\
\hline $\begin{array}{c}\text { NÍVEL «MICRO» } \\
\text { (INDIVÍDUOS/CASAIS } \\
\text { FAMILIAS) }\end{array}$ & $\begin{array}{l}\text { - N. }{ }^{\circ} \text { de filhos intervalo } \\
\text { entre os nascimentos } \\
\text { - Ciclo familiar } \\
\text { - N. } .^{\circ} \text { efectivo de filhos }\end{array}$ & $\begin{array}{l}\text { - Calendário do intervalo } \\
\text { entre os nascimentos } \\
\text { - Estab. conjugal } \\
\text { - Plan. familiar } \\
\text { - N. }{ }^{\circ} \text { de filhos considerado }\end{array}$ & $\begin{array}{l}\text { - Preferências } \\
\text { - Estilo de vida } \\
\text { - Relação de casal } \\
\text { - Estrutura do poder } \\
\text { - N. }{ }^{\circ} \text { de filhos desejado }\end{array}$ & $\begin{array}{l}\text { - Opções } \\
\text { - Condições de vida } \\
\text { - Rendi. absoluto e relativo } \\
\text { - Custos e benefícios dos } \\
\text { filhos }\end{array}$ \\
\hline
\end{tabular}

FONTE: R. MACKENSEN, Social change and reproductive behaviour on continuous transition; Ch. Hohn R. MACKENSEN (a cura di), Determinants of fertility trends: Theories re-examined, Liège, Ordina Editions, IUSSP; FEDERICI, N. Procreazione, famiglia, lavoro della donna, Ed. Loescher Università, Torino, 1984, p. $110-115$. 


\section{QUADRO III}

Percentagens dos métodos anticonceptivos

habitualmente usados pelas mulheres que controlam os nascimentos

\begin{tabular}{|c|c|c|c|c|c|c|c|c|}
\hline PAÍSES & ANOS & 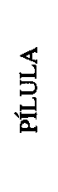 & 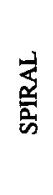 & 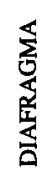 & 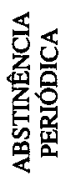 & 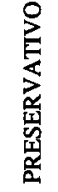 & 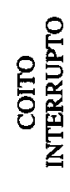 & $\begin{array}{l}\mathscr{8} \\
\stackrel{8}{5} \\
\text { 官 }\end{array}$ \\
\hline FINLÂNDIA & 1971 & 26 & 4 & - & 1 & 40 & 21 & 8 \\
\hline HUNGRIA & 1966 & - & - & 7 & 4 & 16 & 66 & 7 \\
\hline DINAMARCA & 1970 & 37 & 4 & 9 & 2 & 30 & 7 & 11 \\
\hline CHECOSLOVÁQUIA & 1970 & 4 & 14 & - & 3 & 19 & 52 & 8 \\
\hline POLÓNIA & 1972 & 4 & 1 & - & 23 & 17 & 49 & 6 \\
\hline JUGOSLÁVIA & 1970 & 9 & 2 & 一 & 3 & 6 & 73 & 7 \\
\hline FRANÇA & 1972 & 17 & 2 & 1 & 14 & 12 & 52 & 2 \\
\hline ESTADOS UNIDOS & 1970 & 41 & 9 & 7 & 8 & 17 & 3 & 15 \\
\hline BÉLGICA & 1966 & 8 & - & - & 26 & 6 & 51 & 9 \\
\hline INGLATERRA - GAL. & 1967 & 19 & 2 & 6 & 5 & 41 & 25 & 2 \\
\hline PAÍSES BAIXOS & 1969 & 45 & 1 & 2 & 19 & 23 & 9 & 1 \\
\hline ITÁLIA & 1979 & 16 & 3 & - & 14 & 17 & 52 & 7 \\
\hline
\end{tabular}

FONTE: ONU, Fertility an family planning in Europe around 1970. A Comparative study of twelve National Surveys, New York, 1976. Para Itália: P. De SANDRE (a cura di), Indagine sulla fecondità in Itália, Rapporto generale, 1979, Vol. I e II, apud FEDERICI N., Procreazione famiglia, lavoro, della Donna, Ed. Loescher Università, Torino, 1984, p. 67. 